\title{
The Effect of Polarized Training on the Athletic Performance of Male and Female Cross-Country Skiers during the General Preparation Period
}

\author{
Tae Ho Kim ${ }^{1}$, Joung Kyue Han ${ }^{2} \mathbb{D}$, Ji Young Lee ${ }^{3, *}$ and Yong Chul Choi ${ }^{3, *}$ \\ 1 Department of Health Science, Sports for All, Jangan University, Hwaseong 18331, Korea; \\ thgy1125@jangan.ac.kr \\ 2 College of Sports Science, Chung-ang University, Anseong 17546, Korea; jkhan@cau.ac.kr \\ 3 Department of Physical Education, Gangneung-Wonju National University, Gangneung 25457, Korea \\ * Correspondence: jylee@gwnu.ac.kr (J.Y.L.); skicyc@gwnu.ac.kr (Y.C.C.); Tel.: +82-33-640-2556 (J.Y.L. \& Y.C.C.); \\ Fax: +82-33-641-2878 (J.Y.L. \& Y.C.C.)
}

Citation: Kim, T.H.; Han, J.K.; Lee, J.Y.; Choi, Y.C. The Effect of Polarized Training on the Athletic Performance of Male and Female Cross-Country Skiers during the General Preparation Period. Healthcare 2021, 9, 851. https://doi.org/10.3390/ healthcare9070851

Academic Editor: Andreas Konrad

Received: 28 April 2021

Accepted: 30 June 2021

Published: 6 July 2021

Publisher's Note: MDPI stays neutral with regard to jurisdictional claims in published maps and institutional affiliations.

Copyright: (c) 2021 by the authors. Licensee MDPI, Basel, Switzerland. This article is an open access article distributed under the terms and conditions of the Creative Commons Attribution (CC BY) license (https:// creativecommons.org/licenses/by/ $4.0 /)$.

\begin{abstract}
This study aimed to analyze the effect of 12 weeks of polarized training on body composition, cardiorespiratory function, and upper-body power of male and female cross-country skiers during the general preparation period. A total of 16 national cross-country skiers (8 male and 8 female; 8 national cross-country skiers and 8 national biathlon athletes) participated. Polarization training was conducted for 12 weeks from May to July in 2019 during the general preparation period for cross-country skiers. The low-weight, high-repetition method was used for strength training. The effect of the polarized training on body composition, maximum oxygen intake $\left(\mathrm{VO}_{2} \mathrm{max}\right)$, respiratory exchange rate, all-out time, and ski ergometer exercise time was assessed. There was no change in weight, BMI, and muscle mass in male and female cross-country skiers following the 12 weeks of polarized training $(p>0.05)$. Male body fat percentage (pre $18.1 \%$, post $12.7 \%$ ) and female body fat percentage (pre $29.1 \%$, post $21.4 \%$ ) showed a significant decrease $(p<0.05)$. After training, $\mathrm{VO}_{2} \mathrm{max}$ increased by $7.72 \%$ in male athletes (pre $71.05 \mathrm{~mL} / \mathrm{kg} / \mathrm{min}$, post $77.0 \mathrm{~mL} / \mathrm{kg} / \mathrm{min}$ ) and $6.32 \%$ in female athletes (pre $60.26 \mathrm{~mL} / \mathrm{kg} / \mathrm{min}$, post $64.33 \mathrm{~mL} / \mathrm{kg} / \mathrm{min}$ ). Treadmill exercise time increased by $5.39 \%$ for male athletes (pre $1038 \mathrm{~s}$, post $1064 \mathrm{~s}$ ) and 2.23\% for female athletes (pre $855 \mathrm{~s}$, post $874 \mathrm{~s}$ ). However, there was no significant difference between male and female athletes $(p>0.05)$. The 50\% recovery time from the maximum heart rate to the target heart rate decreased by $64.52 \%$ in males (pre $168.8 \mathrm{~s}$, post $102.6 \mathrm{~s}$ ) and $6.48 \%$ in females (pre $135 \mathrm{~s}$, post $129.6 \mathrm{~s}$ ). Significant differences were found only in male athletes $(p<0.05)$. The double-pole $500 \mathrm{~m}$ exercise duration for the ski ergometer significantly decreased after the training for both sexes $(p<0.05)$. In this study, the 12 weeks of polarized training improved the body composition and athletic performance of all cross-country skiers. Interestingly, in this study, we confirmed that polarized training had a better effect on cardiorespiratory function in male cross-country skiers than in female cross-country skiers. Conversely, we found that the outcomes of the ski ergometer exercise factors were more effective in female athletes than in male athletes. Therefore, we insist that when applying a polarized training program to athletes, it should be planned in detail by sex, exercise amount, intensity, and type of training.
\end{abstract}

Keywords: polarized training; anaerobic threshold; endurance fitness; cross-country ski

\section{Introduction}

Cross-country skiing is a sport that requires endurance, as with cycling and running [1-3]. Generally, in endurance sports, the higher the performance, the better the maximum oxygen intake. In cross-country skiing events, world-class athletes are reported to have higher maximum oxygen intake than the national-level athletes [4-6]. In addition, compared to national-level cross-country skiers, world-class cross-country skiers have 
superior anaerobic power, muscular endurance and muscle power, and high aerobic and endurance capabilities [1,7-12].

Therefore, endurance training is very important for cross-country skiers because it improves capillary density, myoglobin content, and mitochondria number and size, which improve maximum oxygen intake, aerobic metabolism, and energy production [13-16]. An important consideration in endurance training is the efficient distribution of exercise intensity, duration, and frequency. Typical endurance training methods including prolonged high-volume, low-intensity exercise, lactate threshold training, low-volume, high-intensity interval training, and polarized (POL) training combine low intensity, high momentum, and low-to-moderate high interval training [17-20]. Successful cross-country skiers use the POL training model to perform endurance training in $85-90 \%$ of their annual exercise, and perform longer low-intensity endurance training compared to national skiers $[2,6,13,21]$. In addition, it is more effective to perform strength training together with endurance training than endurance training only for short-term endurance exercise performance [15,22-24].

All sports events have a training cycle to achieve the best athletic ability in important competitions [25]. Cross-country skiing is also considered to have seasonal characteristics: general preparation period 1 (May to July), general preparation period 2 (August to October), specific preparation period (November to December), and the competition period (January to March) [21,23]. It is important to plan the training program according to the purpose of the training cycle and the individuality of the trainees. The purpose of the general preparation period is to improve the athlete's general fitness level and work capacity and to maximize adaptability in preparation for a high level of training. In addition, excessive high-intensity training and a large volume of training during the preparation period can cause muscle injury and overtraining; therefore, it is necessary to plan appropriate and detailed scientific training [26-30].

There is a lack of research on the correlation between the training cycle and POL training in cross-country skiing. Therefore, this study aimed to plan an annual program for cross-country skiers by analyzing the effects of POL training on body composition, cardiopulmonary function, and the upper-body power of male and female cross-country skiers during the general preparation period (12 weeks) in order to provide basic information about the preparation period.

Additionally, we expected that POL training would have a positive effect on cardiorespiratory function in both male and female athletes. However, we also predicted that exercise time and upper-body strength power would differ due to differences in skeletal muscle mass and body fat percentage.

\section{Methods}

\subsection{Participants}

Sixteen (8 male, 8 female) cross-country skiers from the Korean national team (crosscountry ski and biathlon) participated in this study. This study procedure and informed consent document were approved and reviewed by the Ethics Committee of GangeungWonju National University, Korea (GWNUIRB-2021-11; approval date: 25 February 2021). This research was performed in accordance with the Declaration of Helsinki principles. The physical characteristics of the participants are presented in Table 1.

Table 1. Baseline demographic characteristics of the men and women cross-country skiers.

\begin{tabular}{cccccc}
\hline Sex (n) & Age (yrs) & Height $(\mathbf{c m})$ & Weight $(\mathbf{k g})$ & Body Fat (\%) & Muscle Mass (kg) \\
\hline Male (8) & $22.7 \pm 3.4$ & $171.5 \pm 6.6$ & $72.2 \pm 5.19$ & $18.1 \pm 7.12$ & $34.1 \pm 2.68$ \\
Female (8) & $24.1 \pm 4.3$ & $162 \pm 6.0$ & $57.3 \pm 5.96$ & $25.2 \pm 4.3$ & $29.1 \pm 7.7$ \\
\hline \multicolumn{7}{l}{ Data are presented as mean \pm standard deviation. }
\end{tabular}

\subsection{Design and Procedures}

This experiment was conducted from May to July in 2019 for 12 weeks. To analyze the effect of POL training on the exercise performance of cross-country skiers in the general 
preparation period, we compared and analyzed the following exercise performance factors before and after the training period: the all-out time for body composition, cardiopulmonary function, exercise load test, and the ski ergometer exercise time.

\subsection{Anthropometric Measurements and Body Composition}

Participants' height and body weight were respectively assessed to proximate $0.1 \mathrm{~cm}$ and $0.1 \mathrm{~kg}$. Also, body mass index (BMI) was measured according to the following formula: $\mathrm{kg} / \mathrm{m}^{2}$. Body composition such as body fat and lean mass, and body fat percentage (\%), were measured using bioelectrical impedance analysis (InBody 3.0, Inbody, Korea). Participants' body composition was measured before training and after 12 weeks of POL training. For accurate measurement, measurements were taken without nutrient intake for more than $10 \mathrm{~h}$.

\subsection{Graded Exercise Test}

The maximum exercise test was carried out using respiratory gas separation equipment: Quark CPET (Cosmed Co., Rome, Italy). In addition, the Bruce protocol was used. Exercise tests were conducted until the participants were all-out, and the endpoint was marked by a participant's RPE scale of 17 or more and a respiratory ratio of over 1.15. Additionally, for the safety of athletes, blood pressure and ECG (electrocardiogram) were continuously monitored during the graded exercise test. However, no abnormal ECG rhythms were observed in the athletes participating in the experiment [31-33].

\subsection{Ski Ergometer Test}

To evaluate the participants' exercise time through upper-body muscle power, a maximum upper-body power strength exercise test was performed using a Ski Ergometer (Concept II, Morrisville, NC, USA) [34-36]. Strokes were performed for a total distance of $500 \mathrm{~m}$ using the double-poling technique, and the duration was automatically recorded on the ergometer monitor. Three sets of the tests were evaluated before and after the POL training program with $2 \mathrm{~min}$ of rest per set.

\subsection{Training Program}

POL training utilized the training program suggested for existing cross-country athletes $[13,17,19,37]$. The Polarized training method is a training method that performs $70-80 \%$ of the total amount of exercise at low intensity (HRmax $65-80 \%$ ), $5-10 \%$ at middle intensity (HRmax 80 88\%), and the remaining 15-20\% at high intensity (HRmax 88 100\%). It is the training method that achieves possibly the greatest improvement in the key variables related to the endurance performance of athletes [17,38]. For strength training, low weight and high repetitions were performed, focusing on the tissue adaptation period which accounts for $18 \%$ of the total training volume. The detailed training program is shown in Table 2.

Table 2. Training Program.

\begin{tabular}{cccc}
\hline Day & Variables & A.M. Training & P.M. Training \\
\hline \multirow{3}{*}{ Mon } & Event & Roller Classical & Trekking Run \\
\cline { 2 - 4 } & Time & $\begin{array}{c}40-22-30 \mathrm{~min} \\
\text { speed } 10 \mathrm{~s}(\mathrm{ex}) / 120 \mathrm{~s}(\mathrm{re}) \times 10 \mathrm{set}\end{array}$ & 90 min \\
\cline { 2 - 4 } & Intensity & zone $2-5-1$ & zone 1 \\
\hline \multirow{2}{*}{ Tue } & Event & Roller Skate & Weight Training + Core Training \\
\cline { 2 - 4 } & Time & 40-20-40 min & 90 min \\
\cline { 2 - 4 } & Intensity & zone 2-3-1 & $\begin{array}{c}65 \%(1 \mathrm{RM}) \times 15 \mathrm{rd} \times 3 \text { set } \\
\text { recovery time } 90 \mathrm{~s}\end{array}$ \\
\hline
\end{tabular}


Table 2. Cont.

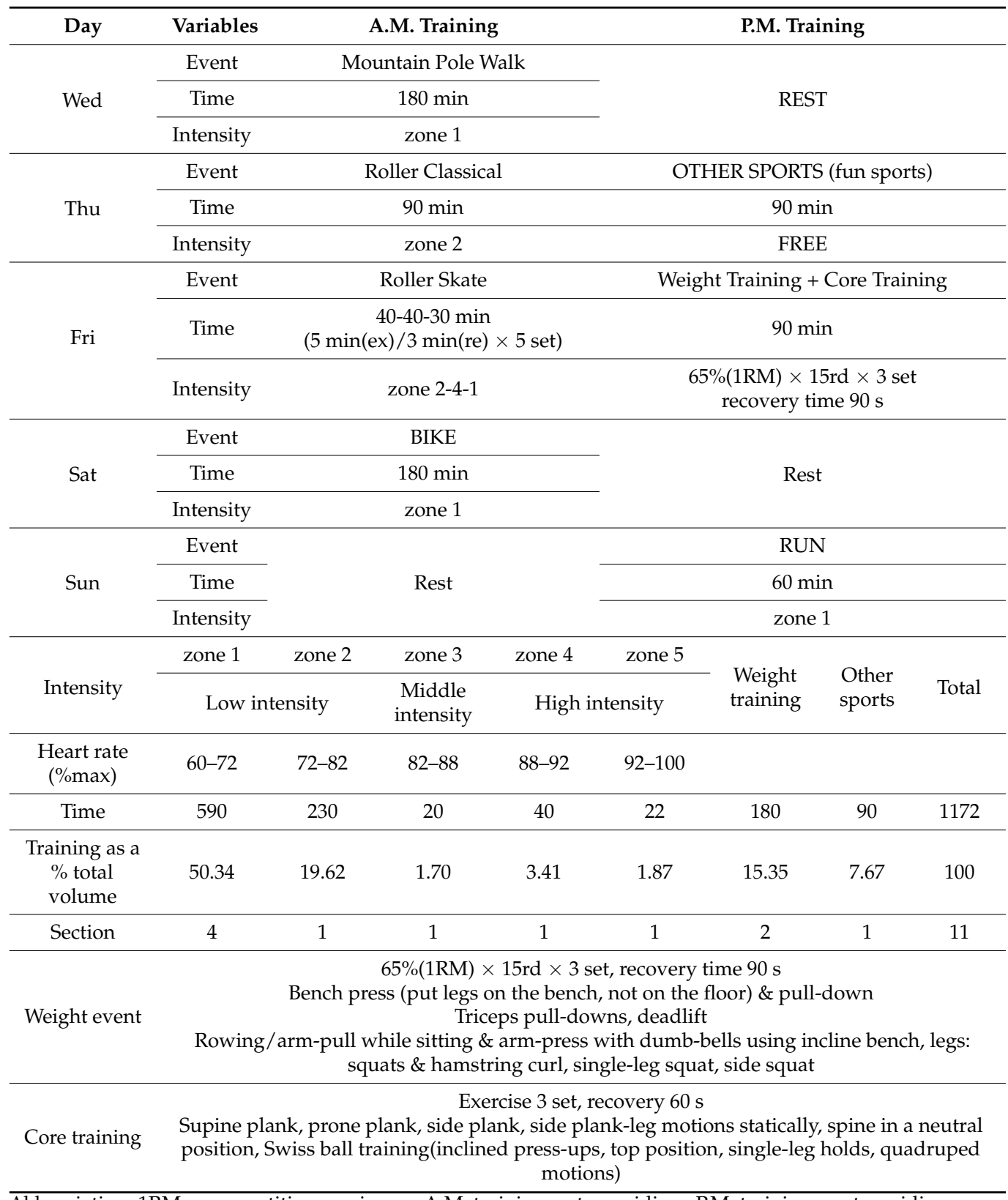

Abbreviation: 1RM, one repetition maximum; A.M. training, ante meridiem; P.M. training, post meridiem.

\subsection{Statistical Analysis}

All statistical analyses were conducted using SPSS Version 20.0 (IBM, Armonk, NY, USA) for Windows. To analyze the effect of the 12 weeks of POL training on body composition, maximum oxygen intake $\left(\mathrm{VO}_{2} \mathrm{max}\right)$, respiratory exchange rate (RER), all-out time, and ski ergometer exercise time, we performed a paired sample $t$-test. In addition, the differences between men and women athletes were compared using a covariance analysis of the Wilcoxon signed rank test. All statistically significant levels were set at $p<0.05$.

\section{Results}

Female cross-country skiers showed statistically significant decreases in weight, BMI, and body fat percentage after 12 weeks of POL training $(p<0.05)$. There was no statistically significant difference in the body weight and BMI of female skiers, but body fat percentage decreased significantly after the POL training $(p<0.05)$. However, for other variables we did not find any significant differences between male and female athletes $(p>0.05)$. 
The maximum oxygen intake increased by $8.37 \%$ for male athletes and $6.75 \%$ for female athletes after the training, but no statistically significant difference was observed $(p>0.05)$. After the training, treadmill exercise time increased by $5.39 \%$ for male athletes and $2.23 \%$ for female athletes. However, there was no significant difference between male and female athletes $(p>0.05)$. The recovery time from the maximum heart rate to the target heart rate of $50 \%$ decreased by $64.52 \%$ in males, with a statistically significant difference $(p<0.05)$; but it decreased by $6.48 \%$ in females, with no statistically significant difference $(p>0.05)$. Excluding ski ergometer 2 set time, the ski ergometer exercise time significantly decreased after the training for both males and females $(p<0.05)$. The above results are shown in Table 3.

Table 3. Changes in anthropometrics, graded exercise test variables, ski ergometer variables between pre- and post-exercise training program.

\begin{tabular}{|c|c|c|c|c|c|c|}
\hline \multirow{2}{*}{ Variables } & \multicolumn{3}{|c|}{ Male } & \multicolumn{3}{|c|}{ Female } \\
\hline & Pre & Post & $p$-Value & Pre & Post & $p$-Value \\
\hline Weight (kg) & $72.2 \pm 5.19$ & $68.8 \pm 4.08$ & 0.079 & $57.3 \pm 5.96$ & $51.1 \pm 3.90$ & 0.120 \\
\hline $\operatorname{BMI}\left(\mathrm{kg} / \mathrm{m}^{2}\right)$ & $24.6 \pm 2.10$ & $23.4 \pm 1.10$ & 0.058 & $21.9 \pm 2.71$ & $19.4 \pm 3.90$ & 0.120 \\
\hline Muscle mass (kg) & $34.1 \pm 2.68$ & $32.6 \pm 5.40$ & 0.916 & $29.1 \pm 7.7$ & $29.1 \pm 7.7$ & 0.263 \\
\hline Body fat (\%) & $18.1 \pm 7.12$ & $12.7 \pm 2.74$ & $0.028 *$ & $25.2 \pm 4.3$ & $21.4 \pm 4.2$ & $0.013 *$ \\
\hline $\mathrm{VO}_{2} \max \left(\mathrm{L} \min ^{-1}\right)$ & $4.95 \pm 0.39$ & $5.17 \pm 0.14$ & 0.069 & $3.16 \pm 0.39$ & $3.28 \pm 0.16$ & 0.069 \\
\hline $\begin{array}{c}\mathrm{VO}_{2} \max \\
\left(\mathrm{mL} / \mathrm{min}^{-1} / \mathrm{kg}^{-1}\right)\end{array}$ & $71.05 \pm 7.90$ & $77.0 \pm 4.49$ & 0.327 & $60.26 \pm 4.20$ & $64.33 \pm 3.29$ & 0.233 \\
\hline HRmax (beat/min) & $192 \pm 9$ & $192 \pm 6$ & 0.833 & $192 \pm 9$ & $193 \pm 11$ & 0.612 \\
\hline $\mathrm{AT}(\mathrm{L} / \mathrm{min})$ & $3.02 \pm 0.84$ & $3.29 \pm 0.90$ & 0.499 & $2.18 \pm 0.35$ & $2.28 \pm 0.21$ & 0.575 \\
\hline ATHR (beat/min) & $155 \pm 20$ & $155 \pm 15$ & 0.735 & $165 \pm 9$ & $170 \pm 11.72$ & 0.121 \\
\hline All-out time (s) & $1038 \pm 46.1$ & $1064 \pm 49.6$ & 0.161 & $855.2 \pm 53.4$ & $874.75 \pm 52.6$ & 0.120 \\
\hline Recovery time (s) & $168.8 \pm 56.1$ & $102.6 \pm 22.9$ & $0.036 *$ & $138 \pm 48.8$ & $129.6 \pm 56.0$ & 0.327 \\
\hline Ski ergometer & & & & & & \\
\hline 1 set time (s) & $122.5 \pm 6.5$ & $117 \pm 2.4$ & $0.028 *$ & $149.3 \pm 20.8$ & $142.6 \pm 8.36$ & 0.263 \\
\hline 2 set time (s) & $123.4 \pm 8.7$ & $121.9 \pm 9.5$ & 0.400 & $155.3 \pm 13.1$ & $144.7 \pm 8.71$ & $0.021 *$ \\
\hline 3 set time (s) & $126.1 \pm 7.0$ & $123.6 \pm 8.9$ & 0.233 & $150.3 \pm 9.73$ & $144.7 \pm 8.46$ & $0.021 *$ \\
\hline
\end{tabular}

${ }^{*} p<0.05$; data are presented as the mean \pm standard deviation. $p$-values were obtained by Wilcoxon signed rank test. Abbreviation: $\mathrm{BMI}$, body mass index; $\mathrm{VO}_{2} \max$, maximal oxygen uptake; HRmax, heart rate maximum; $\mathrm{AT}$ anaerobic threshold; ATHR, anaerobic threshold heart rate.

Meanwhile, we compared all variables and results of male and female athletes using ANCOVA analysis. As a result, after 12 weeks of POL training, it was confirmed that there was a difference between male and female athletes in weight, BMI, body fat percentage, oxygen intake and maximum oxygen intake, and aerobic threshold $(p>0.05)$. However, for other variables, we could not confirm differences between male and female athletes. The above results are shown in Table 4 .

Table 4. Comparison of anthropometrics, graded exercise test variables, ski ergometer variables between pre- and post-exercise training program in skiers.

\begin{tabular}{cccccc}
\hline Variables & Group & Pre & Post & F & $p$-Value \\
\hline \multirow{2}{*}{ Weight $(\mathrm{kg})$} & Male & $72.2 \pm 5.19$ & $68.8 \pm 4.08$ & 17.159 & 0.003 * \\
& Female & $57.3 \pm 5.96$ & $51.1 \pm 3.90$ & & \\
BMI $\left(\mathrm{kg} / \mathrm{m}^{2}\right)$ & Male & $24.6 \pm 2.10$ & $23.4 \pm 1.10$ & 26.487 & $<0.001$ * \\
& Female & $21.9 \pm 2.71$ & $19.4 \pm 3.90$ & & \\
Muscle mass $(\mathrm{kg})$ & Male & $34.1 \pm 2.68$ & $32.6 \pm 5.40$ & 0.456 & 0.511 \\
& Female & $29.1 \pm 7.7$ & $29.1 \pm 7.7$ & & \\
Body fat $(\%)$ & Male & $18.1 \pm 7.12$ & $12.7 \pm 2.74$ & 12.537 & $0.004^{*}$ \\
& Female & $25.2 \pm 4.3$ & $21.4 \pm 4.2$ & & \\
$\mathrm{VO}_{2}(\mathrm{~mL} / \mathrm{kg} / \mathrm{min})$ & Male & $4.95 \pm 0.39$ & $5.17 \pm 0.14$ & 71.925 & $<0.001$ * \\
& Female & $3.16 \pm 0.39$ & $3.28 \pm 0.16$ & & \\
$\mathrm{VO}_{2}$ max $(\mathrm{mL} / \mathrm{kg} / \mathrm{min})$ & Male & $71.05 \pm 7.90$ & $77.0 \pm 4.49$ & 17.718 & $<0.001 *$ \\
& Female & $60.26 \pm 4.20$ & $64.33 \pm 3.29$ & & \\
$\mathrm{HRmax}^{*}(\mathrm{beat} / \mathrm{min})$ & Male & $192 \pm 9$ & $192 \pm 6$ & 0.157 & 0.698 \\
& Female & $192 \pm 9$ & $193 \pm 11$ & & \\
\hline
\end{tabular}


Table 4. Cont.

\begin{tabular}{cccccc}
\hline Variables & Group & Pre & Post & F & $p$-Value \\
\hline \multirow{2}{*}{ AT (L/min) } & Male & $3.02 \pm 0.84$ & $3.29 \pm 0.90$ & \multirow{2}{*}{0.382} & $0.028^{*}$ \\
& Female & $2.18 \pm 0.35$ & $2.28 \pm 0.21$ & & \\
ATHR (beat/min) & Male & $155 \pm 20$ & $155 \pm 15$ & 2.987 & 0.108 \\
& Female & $165 \pm 9$ & $170 \pm 11$ & & \\
All-out time (sec) & Male & $1038 \pm 46.1$ & $1064 \pm 49.6$ & 1.427 & 0.254 \\
& Female & $855.2 \pm 53.4$ & $874.75 \pm 52.6$ & & \\
Recovery time (sec) & Male & $168.8 \pm 56.1$ & $102.6 \pm 22.9$ & \multirow{2}{*}{1.630} & 0.224 \\
& Female & $138 \pm 48.8$ & $129.6 \pm 56.0$ & & \\
\hline
\end{tabular}

${ }^{*} p<0.05$; data are presented as the mean \pm standard deviation. $p$-values were obtained by analysis of convariance. Abbreviations: BMI, body mass index; $\mathrm{VO}_{2} \max$, maximal oxygen uptake; HRmax, heart rate maximum; AT, anaerobic threshold; ATHR, anaerobic threshold heart rate.

\section{Discussion}

In general, it is desirable to establish a control group in order to confirm the effect of training and reduce experimental error. The control group should be provided the equal environmental condition as the experimental group. All participants in this study were trained through the national training center's standardized POL training program; it was almost impossible to find a control group with identical environmental conditions. Therefore, in this study we also tried to compensate for the shortcomings of this study regarding the absence of a control group by comparing male and female athletes.

POL training is an intervention method to improve the performance of endurance athletes [38,39]. In this study, it was confirmed that POL training improved the body weight, body mass index, and body fat percentage of female skiers and influenced the changes in body fat percentage of male skiers. Body composition is the most important factor for health-related physical strength and has a high correlation with the performance of cross-country athletes [40-42]. High weight and body fat percentage negatively affect physical strength factors such as agility and quickness [43]. It is reported that it is important to maintain as much muscle mass and as little body fat percentage as possible in order to have a positive effect on athletes' performance [44]. In a study that analyzed the body composition of athletes of the US Ski Team, the average body fat percentage was $6.1 \%$ in males and $13.1 \%$ in females, and high weight and body fat percentage negatively affected physical strength factors such as agility and quickness [19]. Therefore, it is important for athletes to maintain as much muscle mass as possible and as little body fat as possible in order to observe a positive effect on their performance [23]. It is a common phenomenon that when weight and body fat percentage decrease, muscle mass also decreases. In our study, despite the decrease in body weight and body fat percentage, there was no statistically significant change in muscle mass, which was similar to previous studies that showed the effectiveness of POL training in reducing body fat percentage and increasing muscle mass $[7,12,22]$. However, in most POL training studies, those that classified the training cycles were insufficient. The results of this study suggest that POL training is advantageous in maintaining the muscle mass and effectively controlling the body fat percentage of cross-country skiers during the general preparation period. All participants in this study were provided with the same diet by a nutritionist at the national training center.

Maximum oxygen intake is a measure of an athlete's cardiopulmonary function and is one of the indicators that has a significant impact on sports that require aerobic capacity [45-47]. According to a previous study, the maximum oxygen intake levels for male and female cross-country skiers worldwide are 90-95 and 73-79 mL $/ \mathrm{kg} / \mathrm{min}$, and $\mathrm{VO}_{2}$ is 5.5 to $6.5 \mathrm{~L} / \mathrm{min}$ for men athletes and 4.0 to $5.0 \mathrm{~L} / \mathrm{min}$ for women athletes. These results suggest that the participants' lower $\mathrm{VO}_{2}$ max was slower than that of world-class athletes. [11,48]. The results of this study showed that there was a slight increase in the $\mathrm{VO}_{2}$ max in both males and females after POL training for 12 weeks. These results suggest that POL training can be an important intervention in improving cardiorespiratory function in both male and female skiers during general preparation. According to the training cycle, 
elite sports athletes can change the training volume, training intensity, and training type to improve their performance [49]. Meanwhile, some studies suggested that $\mathrm{VO}_{2}$ max could be improved by increasing the ratio of HIIT(High Intensity Interval Training) and LT(Lactate Threshold) training in POL until the competition period [50,51]. Generally, the increase rate of $\mathrm{VO}_{2}$ max for female athletes was lower than that for male athletes. Therefore, it is necessary to increase the ratio of HIIT and LT training to female athletes when planning POL training during the general preparation period.

Heart rate is a very useful index for predicting the energy system. Also, it is the most basic variable that indicates the activity of exercise intensity and physical stress. Coaches of endurance sports such as cross-country skiing, marathon, and cycling use the monitoring of heart rate to plan training programs $[27,52,53]$. During exercise, maximal oxygen uptake and maximal heart rate form a proportional relationship. However, athletes with higher cardiorespiratory capacity have higher $\mathrm{VO}_{2}$ max and lower heart rates at the same load intensity. It is known that when cardiac output increases, the amount of oxygen to the tissues increases and thus the heart rate decreases. It has been reported that an increase in $\mathrm{VO}_{2}$ max decreases heart rate, which improves exercise records. However, many studies showed that well-trained elite athletes do not experience significant changes in maximum heart rate during high-intensity training [52,54-57]. The steeper the slope, the more the skier's heart rate increases to the level of his maximum heart rate. Therefore, it is important to reduce an athlete's heart rate quickly on flat ground and downhill to win the race $[58,59]$. Although no change in maximum heart rate was observed in our study, we found that heart rate recovered faster in male athletes than in female athletes. Heart rate is related to cardiac output. We suggest that POL training may reduce recovered time to heart rate through the $\mathrm{VO}_{2}$ max increase in male athletes. In addition, we confirmed that the exercise time increased along with the $\mathrm{VO}_{2}$ max of male and female athletes after the POL training program.

In addition to the cardiorespiratory function, the important fitness factors for Nordic skiers are muscle power and endurance [1,60]. A cross-country skier's upper-body strength is one of the important factors for mass start and sprint race performance. Strong upperbody strength is associated with a lower heart rate and has physiological benefits. The ski ergometer not only evaluates cardiorespiratory function, muscle fatigue, and performance, but also improves upper-body strength $[5,23,61]$. The ski ergometer test has two methods of evaluating arrival time and distance. Shorter time and longer distances can be seen as an improvement in upper-body power $[62,63]$. We assessed the upper-body power in male and female athletes using a ski ergometer. As a result of analyzing the effects of POL training and low-weight, high-repetition weight training on the upper-body power of male and female athletes, it was found that both groups of male and female athletes increased speed. In particular, it was found to increase the upper-body power of female athletes more than male athletes. The results of this study can be interpreted as the same as those of a study showing that the physiological adaptability of female athletes was greater than male athletes as a result of ski ergometer training for 33 elite skiers [36]. The POL training and low-weight, high-repetition weight training program applied in this study can be suggested as an effective training program for female athletes in the general preparation period. However, in order to improve the upper-body power of male athletes, it is considered that it is necessary to increase the total weight of the strength program or to perform additional strength training.

Results from this study shows that 12 weeks of POL training positively affect the general quasi-term of cross-country skiers, as shown in previous studies $[3,7,16]$ that reported that the POL training program improves the body composition and physical strength of athletes. To the best of our knowledge, this study is the first to report on the effectiveness of POL training in Asian women athletes.

On the other hand, in this study, to compare the differences between male and female athletes regarding the effects of POL training after 16 weeks of POL training, pre-measured values for various variables for male and female cross-country skiers were covariance- 
processed, and then the difference between before and after each variable was analyzed. It was possible to confirm the difference between male and female athletes in changes in body weight, body mass index, and body fat percentage. Furthermore, variations in the body weight and BMI of female cross-country skiers were slightly larger than those of male skiers, and there were no variation differences in muscle mass between male and female cross-country skiers. The body fat percentage of male cross-country skiers significantly decreased after the training period compared to female cross-country skiers. These results suggest that POL training is helpful in improving and maintaining the body composition of both male and female athletes; but they also suggest that men cross-country skiers' body fat percentage can be significantly reduced to improve athletic performance. Results that disprove these findings exist in our study results, and it was confirmed that the recovery time (heart rate beat) and $\mathrm{VO}_{2}$ max values-the most representative variables that measure cardiopulmonary function-improved significantly in male athletes after the training period compared to female athletes. This implies that POL training can improve the cardiopulmonary function of male cross-country skiers more than that of female crosscountry skiers. Interestingly, in this study, we found that female athletes were more effective than male athletes in ski ergometer exercises that assessed upper-body strength and muscular endurance. Therefore, we suggest that it is necessary to apply the training program differently for male and female athletes when planning the POL training program during the general preparation period. This study suggests that polarized training will help in the planning of training programs for women and men athletes. This study has one limitation. The sample size used in this study is very small, which is due to the limited number of Korean national cross country skiers above the age of 20 years.

\section{Conclusions}

From this study we confirmed that 12 weeks of polarized training had a positive effect on the body composition of male and female cross-country skiers. In addition, it was confirmed that it contributed to the improvement in the athletic performance of crosscountry skiers by improvement of cardiorespiratory function and upper-body strength. Furthermore, our study found that polarized training had a better effect on cardiorespiratory function in male cross-country skiers than in female cross-country skiers. The ski ergometer exercise, which evaluates upper-body strength and muscular endurance, was found to be more effective for female athletes than male athletes. Therefore, to implement the polarized training program, it is necessary to separate male and female athletes and plan in detail the amount of training, training intensity, and type of training required.

Author Contributions: Conceptualization, T.H.K. and Y.C.C.; methodology, J.K.H.; formal analysis, J.K.H.; investigation, T.H.K.; writing—original draft preparation, T.H.K. and Y.C.C.; writing-review and editing, J.K.H. and J.Y.L.; supervision, Y.C.C. and J.Y.L. All authors have read and agreed to the published version of the manuscript.

Funding: There was no support or funding from any individual or organization to conduct this study.

Institutional Review Board Statement: The study was conducted according to the guidelines of the Declaration of Helsinki, and approved by the Institutional Review Board of Gangeung-Wonju National University, Korea (GWNUIRB-2021-11; approval date: 25 February 2021).

Informed Consent Statement: Informed consent was obtained from all subjects involved in the study.

Data Availability Statement: The data are not publicly available due to privacy and ethical reasons.

Conflicts of Interest: The authors declare that there are no potential conflicts of interest with respect to the research, authorship, and/or publication of this article. 


\section{References}

1. Mahood, N.V.K.; Robert, W.; Kertzer, R.; Quinn, T.J. Physiological determinants of cross-country ski racing performance. Med. Sci. Sports Exerc. 2001, 33, 1379-1384. [CrossRef]

2. Sandbakk, Ø.; Holmberg, H.-C. A reappraisal of success factors for Olympic cross-country skiing. Int. J. Sports Physiol. Perform. 2014, 9, 117-121. [CrossRef]

3. Sandbakk, Ø.; Ettema, G.; Holmberg, H.-C. Gender differences in endurance performance by elite cross-country skiers are influenced by the contribution from poling. Scand. J. Med. Sci. Sports 2014, 24, 28-33. [CrossRef] [PubMed]

4. Holmberg, H.C.; Rosdahl, H.; Svedenhag, J. Lung function, arterial saturation and oxygen uptake in elite cross country skiers: Influence of exercise mode. Scand. J. Med. Sci. Sports 2007, 17, 437-444. [CrossRef] [PubMed]

5. Jones, A.M.; Carter, H. The effect of endurance training on parameters of aerobic fitness. Sports Med. 2000, 29, 373-386. [CrossRef] [PubMed]

6. Sandbakk, Ø.; Holmberg, H.-C.; Leirdal, S.; Ettema, G. The physiology of world-class sprint skiers. Scand. J. Med. Sci. Sports 2011, 21, e9-e16. [CrossRef]

7. Staib, J.L.; Im, J.; Caldwell, Z.; Rundell, K.W. Cross-country ski racing performance predicted by aerobic and anaerobic double poling power. J. Strength Cond. Res. 2000, 14, 282-288.

8. Stöggl, T.; Mueller, E.; Ainegren, M.; Holmberg, H.-C. General strength and kinetics: Fundamental to sprinting faster in cross country skiing? Scand. J. Med. Sci. Sports 2011, 21, 791-803. [CrossRef] [PubMed]

9. McGawley, K.; Holmberg, H.-C. Aerobic and anaerobic contributions to energy production among junior male and female cross-country skiers during diagonal skiing. Int. J. Sports Physiol. Perform. 2014, 9, 32-40. [CrossRef] [PubMed]

10. Akay, M.F.; About, F.; Özçiloğlu, M.; Heil, D. Identifying the discriminative predictors of upper body power of cross-country skiers using support vector machines combined with feature selection. Neural Comput. Appl. 2016, 27, 1785-1796. [CrossRef]

11. Danielsen, J.; Sandbakk, Ø.; McGhie, D.; Ettema, G. The effect of exercise intensity on joint power and dynamics in ergometer double-poling performed by cross-country skiers. Hum. Mov. Sci. 2018, 57, 83-93. [CrossRef]

12. Terzis, G.; Stattin, B.; Holmberg, H.-C. Upper body training and the triceps brachii muscle of elite cross country skiers. Scand. J. Med. Sci. Sports 2006, 16, 121-126. [CrossRef]

13. Sandbakk, Ø.; Hegge, A.M.; Losnegard, T.; Skattebo, Ø.; Tønnessen, E.; Holmberg, H.-C. The physiological capacity of the world's highest ranked female cross-country skiers. Med. Sci. Sports Exerc. 2016, 48, 1091-1100. [CrossRef] [PubMed]

14. Tonkonogi, M.; Walsh, B.; Svensson, M.; Sahlin, K. Mitochondrial function and antioxidative defence in human muscle: Effects of endurance training and oxidative stress. J. Physiol. 2000, 528, 379-388. [CrossRef] [PubMed]

15. Aagaard, P.; Andersen, J.L. Effects of strength training on endurance capacity in top-level endurance athletes. Scand. J. Med. Sci. Sports 2010, 20, 39-47. [CrossRef] [PubMed]

16. Docherty, D.; Sporer, B. A proposed model for examining the interference phenomenon between concurrent aerobic and strength training. Sports Med. 2000, 30, 385-394. [CrossRef] [PubMed]

17. Stöggl, T.; Sperlich, B. Polarized training has greater impact on key endurance variables than threshold, high intensity, or high volume training. Front. Physiol. 2014, 5, 33. [CrossRef]

18. Seiler, K.S.; Kjerland, G.Ø. Quantifying training intensity distribution in elite endurance athletes: Is there evidence for an "optimal" distribution? Scand. J. Med. Sci. Sports 2006, 16, 49-56. [CrossRef]

19. Rønnestad, B.R.; Hansen, J.; Thyli, V.; Bakken, T.A.; Sandbakk, Ø. 5-week block periodization increases aerobic power in elite cross-country skiers. Scand. J. Med. Sci. Sports 2016, 26, 140-146. [CrossRef]

20. Gorostiaga, E.M.; Walter, C.B.; Foster, C.; Hickson, R.C. Uniqueness of interval and continuous training at the same maintained exercise intensity. Eur. J. Appl. Physiol. Occup. Physiol. 1991, 63, 101-107. [CrossRef]

21. Solli, G.S.; Tønnessen, E.; Sandbakk, Ø. The training characteristics of the world's most successful female cross-country skier. Frontiers Physiol. 2017, 8, 1069. [CrossRef]

22. Hoff, J.; Gran, A.; Helgerud, J. Maximal strength training improves aerobic endurance performance. Scand. J. Med. Sci. Sports 2002, 12, 288-295. [CrossRef]

23. Losnegard, T.; Mikkelsen, K.; Rønnestad, B.R.; Hallén, J.; Rud, B.; Raastad, T. The effect of heavy strength training on muscle mass and physical performance in elite cross country skiers. Scand. J. Med. Sci. Sports 2011, 21, 389-401. [CrossRef]

24. Storen, O.; Helgerud, J.; Stoa, E.M.; Hoff, J. Maximal strength training improves running economy in distance runners. Med. Sci. Sports Exerc. 2008, 40, 1089-1094. [CrossRef] [PubMed]

25. García-Pallarés, J.; García-Fernández, M.; Sánchez-Medina, L.; Izquierdo, M. Performance changes in world-class kayakers following two different training periodization models. Eur. J. Appl. Physiol. 2010, 110, 99-107. [CrossRef] [PubMed]

26. Seiler, $\mathrm{S}$. What is best practice for training intensity and duration distribution in endurance athletes? Int. J. Sports Physiol. Perform. 2010, 5, 276-291. [CrossRef]

27. Plews, D.J.; Laursen, P.B.; Kilding, A.E.; Buchheit, M. Heart-rate variability and training-intensity distribution in elite rowers. Int. J. Sports Physiol. Perform. 2014, 9, 1026-1032. [CrossRef]

28. Hausswirth, C.; Louis, J.; Aubry, A.; Bonnet, G.; Duffield, R.; Le Meur, Y. Evidence of disturbed sleep and increased illness in overreached endurance athletes. Med. Sci. Sports Exerc. 2014, 46, 1036-1045. [CrossRef]

29. Turner, A. The science and practice of periodization: A brief review. Strength Cond. J. 2011, 33, 34-46. [CrossRef] 
30. Lyakh, V.; Mikołajec, K.; Bujas, P.; Litkowycz, R. Review of Platonov's “Sports Training Periodization. General Theory and its Practical Application"-Kiev: Olympic Literature, 2013. J. Hum. Kinet. 2014, 44, 259-263. [CrossRef] [PubMed]

31. George, J.D.; Paul, S.L.; Hyde, A.; Bradshaw, D.I.; Vehrs, P.R.; Hager, R.L.; Yanowitz, F.G. Prediction of maximum oxygen uptake using both exercise and non-exercise data. Meas. Phys. Educ. Exerc. Sci. 2009, 13, 1-12. [CrossRef]

32. Bruce, R.A.; Kusumi, F.; Hosmer, D. Maximal oxygen intake and nomographic assessment of functional aerobic impairment in cardiovascular disease. Am. Heart J. 1973, 85, 546-562. [CrossRef]

33. Will, P.M.; Walter, J.D. Exercise testing: Improving performance with a ramped Bruce protocol. Am. Heart J. 1999, $138,1033-1037$. [CrossRef]

34. Klusiewicz, A.; Faff, J.; Starczewska-Czapowska, J. Prediction of maximal oxygen uptake from submaximal and maximal exercise on a ski ergometer. Biol. Sport 2011, 28, 31-35. [CrossRef]

35. Bortolan, L.; Pellegrini, B.; Finizia, G.; Schena, F. Assessment of the reliability of a custom built Nordic Ski Ergometer for cross-country skiing power test. J. Sports Med. Phys. Fit. 2008, 48, 177-182.

36. Carlsson, T.; Wedholm, L.; Nilsson, J.; Carlsson, M. The effects of strength training versus ski-ergometer training on double-poling capacity of elite junior cross-country skiers. Eur. J. Appl. Physiol. 2017, 117, 1523-1532. [CrossRef]

37. Choi, Y.C.; Kim, J.K. The Effect of Short-Term Summer Ski Training on Body Composition, Physical Fitness, and Isokinetic Muscle Function of Cross-Country Skiers. J. Mens Health 2020, 16, e63-e74.

38. Neal, C.M.; Hunter, A.M.; Brennan, L.; O'Sullivan, A.; Hamilton, D.L.; DeVito, G.; Galloway, S.D.R. Six weeks of a polarized training-intensity distribution leads to greater physiological and performance adaptations than a threshold model in trained cyclists. J. Appl. Physiol. 2013, 114, 461-471. [CrossRef] [PubMed]

39. Rosenblat, M.A.; Perrotta, A.S.; Vicenzino, B. Polarized vs. threshold training intensity distribution on endurance sport performance: A systematic review and meta-analysis of randomized controlled trials. J. Strength Cond. Res. 2019, 33, 3491-3500. [CrossRef] [PubMed]

40. Rodriguez, N.R.; Di Marco, N.M.; Langley, S. American College of Sports Medicine position stand. Nutrition and athletic performance. Med. Sci. Sports Exerc. 2009, 41, 709. [PubMed]

41. Loucks, A.B. Energy balance and body composition in sports and exercise. J. Sports Sci. 2004, 22, 1-14. [CrossRef]

42. Silvestre, R.; West, C.; Maresh, C.M.; Kraemer, W.J. Body Composition and Physical Performance in Men's Soccer: Astudy Of A National Collegiate Athletic Association Division Iteam. J. Strength Cond. Res. 2006, 20, 177-183. [CrossRef] [PubMed]

43. Fleck, S.J. Body composition of elite American athletes. Am. J. Sports Med. 1983, 11, 398-403. [CrossRef] [PubMed]

44. Stöggl, T.; Enqvist, J.; Müller, E.; Holmberg, H.-C. Relationships between body composition, body dimensions, and peak speed in cross-country sprint skiing. J. Sports Sci. 2010, 28, 161-169. [CrossRef]

45. Ranković, G.; Mutavdžić, V.; Toskić, D.; Preljević, A.; Kocić, M.; Nedin-Ranković, G.; Damjanović, N. Aerobic capacity as an indicator in different kinds of sports. Bosn. J. Basic Med. Sci. 2010, 10, 44. [CrossRef]

46. Ponorac, N.; Matavulj, A.; Grujić, N.; Rajkovača, Z.; Kovačević, P. Maximal oxygen uptake (VO2max) as the indicator of physical working capacity in sportsmen. Acta Med. Median. 2005, 44, 17-20.

47. Durkalec-Michalski, K.; Podgorski, T.; Sokolowski, M.; Jeszka, J. Relationship between body composition indicators and physical capacity of the combat sports athletes. Arch. Budo 2016, 12, 247-256.

48. Rusko, H. Handbook of Sports Medicine and Science, Cross Country Skiing; Blackwell Publishing: Hoboken, NJ, USA, $2008 ;$ pp. 1-31.

49. Fleck, S.J. Periodized strength training: A critical review. J. Strength Cond. Res. 1999, 13, 82-89. [CrossRef]

50. Daussin, F.N.; Zoll, J.; Dufour, S.P.; Ponsot, E.; Lonsdorfer-Wolf, E.; Doutreleau, S.; Mettauer, B.; Piquard, F.; Geny, B.; Richard, R. Effect of interval versus continuous training on cardiorespiratory and mitochondrial functions: Relationship to aerobic performance improvements in sedentary subjects. Am. J. Physiol. Regul. Integr. Comp. Physiol. 2008, 295, R264-R272. [CrossRef] [PubMed]

51. Astorino, T.A.; Edmunds, R.M.; Clark, A.; King, L.; Gallant, R.A.; Namm, S.; Fischer, A.; Wood, K.M. High-intensity interval training increases cardiac output and $\mathrm{VO}_{2}$ max. Med. Sci. Sports Exerc. 2017, 49, 265-273. [CrossRef]

52. Jeukendrup, A.; Diemen, A.V. Heart rate monitoring during training and competition in cyclists. J. Sports Sci. 1998, 16, 91-99. [CrossRef]

53. Achten, J.; Jeukendrup, A.E. Heart rate monitoring. Sports Med. 2003, 33, 517-538. [CrossRef] [PubMed]

54. Benson, R.; Connolly, D. Heart Rate Training; Human Kinetics: Champaign, IL, USA, 2019.

55. Sylta, Ø.; Tønnessen, E.; Seiler, S. From heart-rate data to training quantification: A comparison of 3 methods of training-intensity analysis. Int. J. Sports Physiol. Perform. 2014, 9, 100-107. [CrossRef] [PubMed]

56. Levine, B.D.; Stray-Gundersen, J. "Living high-training low": Effect of moderate-altitude acclimatization with low-altitude training on performance. J. Appl. Physiol. 1997. [CrossRef]

57. Truijens, M.J.; Toussaint, H.M.; Dow, J.; Levine, B.D. Effect of high-intensity hypoxic training on see-level swimming performances. J. Appl. Physiol. 2003, 94, 733-743. [CrossRef] [PubMed]

58. Lee, B.W.; Kim, J.K.; Kwon, H.J.; Choi, Y.C. Effects of Living Low and Training High on Body Composition, Exercise Performance, Blood CK, Lactate and Oxidative Stress Makers Responses in Cross Country Skiers. J. Sports Leis. Stud. 2013, 53, 659-710.

59. Larsson, P.; Olofsson, P.; Jakobsson, E.; Burlin, L.; Henriksson-Larsén, K. Physiological predictors of performance in cross-country skiing from treadmill tests in male and female subjects. Scand. J. Med. Sci. Sports 2002, 12, 347-353. [CrossRef] 
60. MacDougall, J.D.; Wenger, H.A. Physiological Testing of the High-Performance Athlete; Human Kinetics Books: Champaign, IL, USA, 1991.

61. Alsobrook, N.G.; Heil, D.P. Upper body power as a determinant of classical cross-country ski performance. Eur. J. Appl. Physiol. 2009, 105, 633-641. [CrossRef] [PubMed]

62. Forbes, S.C.; Chilibeck, P.D.; Craven, B.; Bhambhani, Y. Comparison of a double poling ergometer and field test for elite cross country sit skiers. N. Am. J. Sports Phys. Ther. NAJSPT 2010, 5, 40.

63. Fukuda, D.H.; Hetrick, R.P.; Kendall, K.L.; Smith-Ryan, A.E.; Jackson, M.E.; Stout, J.R. Characterization of the work-time relationship during cross-country ski ergometry. Physiol. Meas. 2013, 35, 31. [CrossRef] [PubMed] 